\title{
A Novel Slotless Halbach-Array Permanent-Magnet Brushless DC Motor for Spacecraft Applications
}

\author{
R. P. Praveen, M. H. Ravichandran, V. T. Sadasivan Achari, V. P. Jagathy Raj, G. Madhu, and G. R. Bindu
}

\begin{abstract}
This paper presents the design and analysis of a novel machine family - the enclosed-rotor Halbach-array permanentmagnet brushless dc motors for spacecraft applications. The initial design, selection of major parameters, and air-gap magnetic flux density are estimated using the analytical model of the machine. The proportion of the Halbach array in the machine is optimized using finite element analysis to obtain a near-trapezoidal flux pattern. The machine is found to provide uniform air-gap flux density along the radius, thus avoiding circulating currents in stator conductors and thereby reducing torque ripple. Furthermore, the design is validated with experimental results on a fabricated machine and is found to suit the design requirements of critical spacecraft applications.
\end{abstract}

Index Terms-Brushless de motor, coreless, enclosed rotor, finite element analysis, Halbach array, zero cogging.

\section{INTRODUCTION}

$\mathbf{T}$ HE MOST important design consideration in the choice of low-speed high-performance torquer motors for spacecraft applications is not only high torque density and efficiency but also minimum torque ripple and its related harmonics. The effects of torque ripple are undesirable in critical spacecraft applications that require positional accuracy of less than an arc second [1], [2]. They also lead to speed oscillations which cause deterioration in the performance. Moreover, they may excite resonances in the mechanical portion of the drive system, producing acoustic noise [3]. Hence, this paper proposes a novel design for permanent magnet (PM) brushless dc (BLDC) (PMBLDC) motors so that the requirement of high torque density and efficiency is achieved along with the reduction of torque ripple and associated problems.

However, this cannot be easily achieved by utilizing the existing conventional design techniques. Hence, a novel design procedure is developed based on the analysis of the performance of enclosed-rotor Halbach-array PMBLDC machines.

This class of machines is found to be suitable for critical space applications such as in a control moment gyroscope $(\mathrm{CMG})$ and a torquer for space robots which warrants the utmost accuracy and least value of cogging torque. Although a

Manuscript received October 30, 2010; revised March 28, 2011; accepted June 2, 2011. Date of publication June 30, 2011; date of current version April 13, 2012.

R. P. Praveen, V. P. Jagathy Raj, and G. Madhu are with the Cochin University of Science and Technology, Cochin 682022, Kerala, India (e-mail: pravi_8200@yahoo.co.in; jagathy@cusat.ac.in; profmadhu@ rediffmail.com).

M. H. Ravichandran and V. T. Sadasivan Achari are with the Indian Space Research Organisation (ISRO) Inertial Systems Unit, Trivandrum 695013, India (e-mail: mh_ravichandran@vssc.gov.in; vt_sadasivan@vssc.gov.in).

G. R. Bindu is with the College of Engineering Trivandrum, University of Kerala, Trivandrum 695016, Kerala, India (e-mail: bgr100@gmail.com).

Digital Object Identifier 10.1109/TIE.2011.2161058 few core-type radial-flux dual-rotor [4], [5] and dual-stator PM machines [6] have been reported, the possibility of an enclosedrotor coreless configuration utilizing a Halbach array has not been investigated in detail.

BLDC motors have been proven to provide the best allaround performance for aerospace applications because of their long life, high torque, high efficiency, and low heat dissipation [7]. A stepper motor which is a special case of BLDC motors cannot be used for critical spacecraft applications because of its high ripple torque production [8]. Moreover, the earlier works carried out by the authors [9], [10] clearly reveal the magnitude of the detent torque present in the stepper motor which is almost $13 \%$ of the developed torque. PMBLDC motors also give rise to ripple torque which includes the cogging torque produced by the machine and the commutation torque associated with drive circuits. Cogging is one of the disadvantages faced in the slotted motor design, as it causes a ripple in the torque generated by the motor [11]. Cogging torque is caused by the variation of the magnetic energy stored in the air gap, due to the PM flux with the angular position of the rotor. It is due to the interaction between the rotor magnetic flux and the variation of stator reluctance caused by slotting. A slotless BLDC motor design, on the other hand, eliminates the tooth ripple component of cogging and also produces very little slot harmonic effects, thereby facilitating the production of smooth output torque required for the application. However, the output torque generated by the slotless motor is low compared to that by an equivalent slotted one due to its large air gap [12]-[14]. Halbach magnetization can thus be used to compensate for this reduced output as it gives rise to strong and uniform magnetic field [15].

\section{ENCLOSED-Rotor HALbACH-ARRAY PMBLDC MOTOR}

An enclosed-rotor Halbach-array PMBLDC motor employs slotless stator winding unlike the conventional slotted-type PMBLDC motors. The concentrated type of winding is employed due to the advantage of nonoverlapping of phase windings. Being air cored, this machine possesses zero cogging torque and zero stiction. The introduction of flux-focusing magnet eliminates the flux through the rotor iron core and, hence, the core loss. In addition to that, the mean air-gap flux density also increases, resulting in high torque. One of the main challenges faced in the design of low-speed single-rotor coreless machines is the existence of circulating currents in the stator conductors. This can be attributed to the variation of the flux linking these conductors across the large air gap of the machine. 


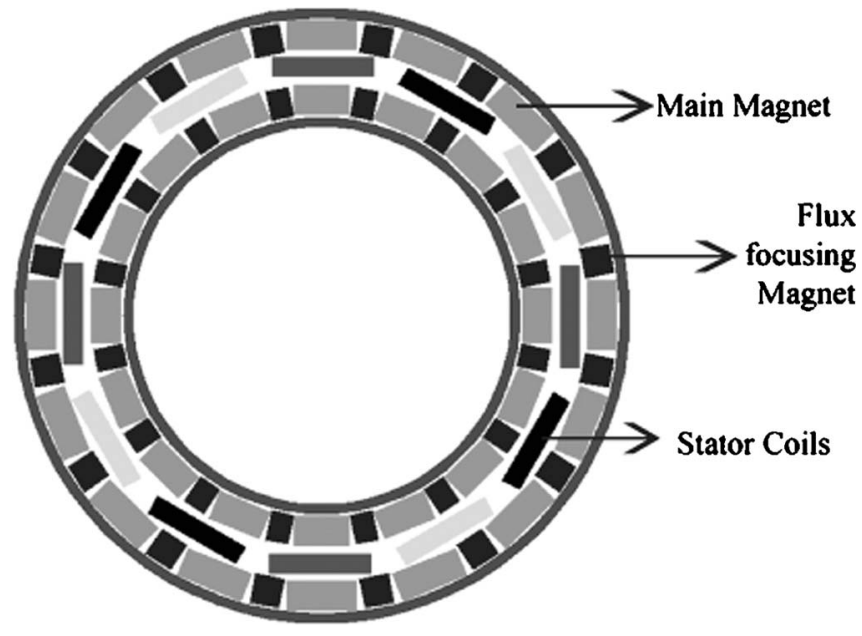

Fig. 1. Enclosed-rotor PMBLDC motor with Halbach array.

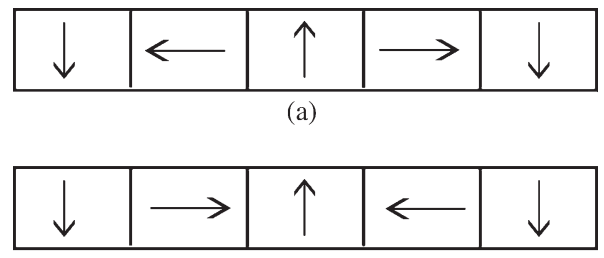

(b)

Fig. 2. Halbach PM array with two segments per pole for (a) external rotor and (b) internal rotor.

The enclosed-rotor Halbach-array PMBLDC motor provides uniform air-gap flux along the radius of the machine, thus eliminating circulating currents in stator conductors. With these advantages, this machine is an ideal candidate for low-speed high-torque spacecraft applications that require positional accuracy of less than an arc second. Fig. 1 shows an enclosed-rotor zero-cogging PMBLDC motor with a Halbach array. The inherent self-shielding property of the Halbach array is utilized in the design as it permits the use of coreless configuration permitting a high torque-to-inertia ratio. Fig. 2 shows the Halbach PM array for the external rotor and internal rotor of the enclosedrotor motor with two segments per pole in which the direction of Halbach magnetization is indicated by the orientation of arrows. In this paper, the design developed is for a typical application of actuating the gimbal of a CMG.

The dimension of the machine is constrained by the available space in the launch vehicle. Hence, as per the requirements of this specific spacecraft application, the outer diameter and axial length of the machine have been limited to 123 and $40 \mathrm{~mm}$, respectively.

\section{Analytical Modeling of the Machine}

There are different types of analytical methods that can be used for the design of electric motors. The most commonly used methods are the method of images, analysis using tensors, and solutions using magnetic vector potential. The analytical method employed in this paper uses scalar magnetic potentials derived from the solutions of Laplace's and Poisson's equations. The general schematic of the machine shown in Fig. 3

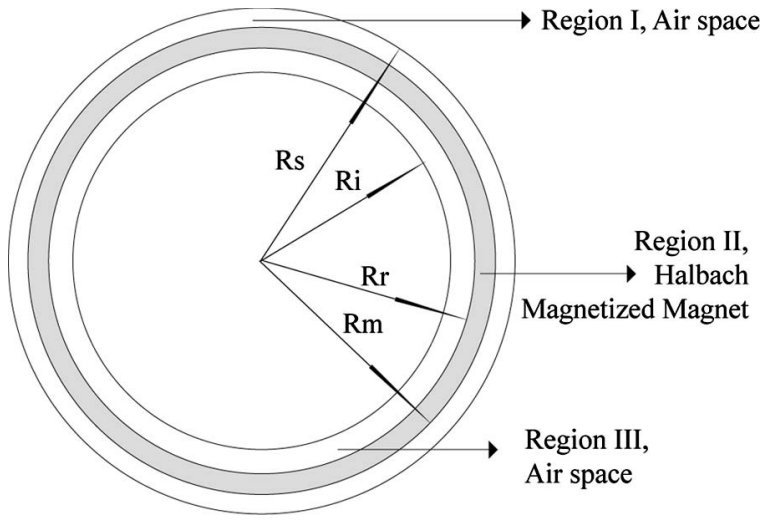

Fig. 3. General schematic diagram of a coreless Halbach-array PMBLDC motor.

is divided into three annular regions, in which region II is the Halbach magnetized magnets and the other regions are airspaces. Windings can be inserted in either region I or III, depending upon interior or exterior configurations. In order to obtain analytical solution for the field distribution produced in a multipole Halbach machine, the following assumptions are made.

1) The magnet is oriented according to Halbach magnetization and is fully magnetized in the direction of magnetization.

2) The effect of finite axial length is neglected.

3) The back iron is infinitely permeable.

Here, for the analytical modeling, the enclosed-rotor configuration is approximated as the sum of coreless internaland external-rotor machines. In the case of the internal-rotor machine, the region inside the Halbach array is considered as air $(R i=0)$, and in the external-rotor machine, the region outside the Halbach array is considered as $\operatorname{air}(R s=\infty)$, where $R i$ and $R s$ are the stator inner bore and outer bore radii, respectively.

The field vectors $\mathbf{B}$ and $\mathbf{H}$ are coupled by

$$
\begin{aligned}
& \mathbf{B}=\mu_{0} \mathbf{H}, \text { in airspace } \\
& \mathbf{B}=\mu_{0} \mu_{r} \mathbf{H}+\mu_{0} \mathbf{M}, \text { in the } \mathbf{P} \mathbf{M}
\end{aligned}
$$

where $\mu_{0}$ is the permeability of free space, $\mu_{r}$ is the relative permeability of the magnet, and $\mathbf{M}$ is the magnetization vector. For an ideal Halbach magnetized machine, the magnetic distribution $\mathbf{M}$ varies sinusoidally. In cylindrical coordinates, it is given by

$$
\mathbf{M}=M_{r} \mathbf{r}+M_{\theta} \theta .
$$

Hence, for an ideal Halbach machine

$$
\mathbf{M}=M \cos p \theta \mathbf{r} \pm M \sin p \theta \theta
$$

where "+" and "-" are for the external and internal Halbach rotor approximations, respectively, $M$ is the amplitude of magnetization which is equal to $B r / \mu_{0}, B r$ is the remanent flux density of the magnet, and $\mathbf{r}$ and $\boldsymbol{\theta}$ are the magnetic vectors in the radial and the circumferential direction, respectively. 
The governing Laplacian (in air gap) and quasi-Poissonian (in magnets) equations, in cylindrical coordinates, are given by

$$
\begin{aligned}
\nabla^{2} \varnothing I= & \frac{\partial^{2} \varnothing I}{\partial r^{2}}+\frac{1}{r} \frac{\partial \varnothing I}{\partial r}+\frac{1}{r^{2}} \frac{\partial^{2} \varnothing I}{\partial \theta^{2}}=0 \\
& \text { In air gap, i.e., }(R m<r<R s) \\
\nabla^{2} \varnothing I I= & \frac{\partial^{2} \varnothing I I}{\partial r^{2}}+\frac{1}{r} \frac{\partial \varnothing I I}{\partial r}+\frac{1}{r^{2}} \frac{\partial^{2} I I}{\partial \theta^{2}}=\frac{\operatorname{div} \mathbf{M}}{\mu_{r}} \\
& \text { In the magnets, i.e., }(R r<r<R m) \\
\nabla^{2} \varnothing I I I= & \frac{\partial^{2} \varnothing I I I}{\partial r}+\frac{1}{r} \frac{\partial \varnothing I I I}{\partial r}+\frac{1}{r^{2}} \frac{\partial^{2} \varnothing I I I}{\partial \theta^{2}} \\
& \text { In air gap, i.e., }(R i<r<R r)
\end{aligned}
$$

where $\Phi I$ and $\Phi I I I$ are the scalar magnetic potentials in the air gap and $\Phi I I$ is that in the magnets. The magnetization source for $(5 b)$ is given as

$$
\operatorname{div} \mathbf{M}=\frac{M_{r}}{r}+\frac{\partial M_{r}}{\partial r}+\frac{1}{r} \frac{\partial M_{\theta}}{\partial \theta} .
$$

The boundary conditions to solve the above governing equations are defined by (7)-(12)

$$
\begin{aligned}
H_{\theta I} \text { at }(r=R s) & =0 \\
H_{\theta I I I} \text { at }(r=R i) & =0 \\
B_{r l} & =B_{r I I} \text { at }\left(r=R_{m}\right) \\
B_{r I I} & =B_{r I I I} \text { at }\left(r=R_{r}\right) \\
H_{\theta I} & =H_{\theta I I} \text { at }\left(r=R_{m}\right) \\
H_{\theta I I} & =H_{\theta I I I} \text { at }\left(r=R_{r}\right) .
\end{aligned}
$$

The magnetic field intensity vector $\mathbf{H}$ can be related to the scalar magnetic potential by

$$
\begin{aligned}
\mathbf{H} & =-\operatorname{grad} \varnothing \\
H_{\mathbf{r}} & =-\frac{\partial \varnothing}{\partial r} ; \quad H_{\theta}=-\frac{1}{r} \frac{\partial \varnothing}{\partial \theta} .
\end{aligned}
$$

Hence, the complete solution for the enclosed-rotor Halbacharray zero-cogging motor under study is obtained by the solution of Laplace's and quasi-Poisson's equations given by (5a)-(5c) and by the application of boundary conditions (7)-(12). The analytical equations are derived in line with [16] and [17]. For an internal-rotor coreless zero-cogging Halbacharray motor, the radial flux density at the air gap $B_{r I}$ is given by

$$
\begin{aligned}
B_{r I}=\frac{-4 B r p}{M_{0}(1+p)}(1+\mu r) \times\left[1-\left(\frac{R r}{R m}\right)^{p+1}\right] \\
\times\left[\left(\frac{r}{R s}\right)^{p-1}\left(\frac{R m}{R s}\right)^{p+1}+\left(\frac{R m}{r}\right)^{p+1}\right] \cos p \theta
\end{aligned}
$$

where $M_{0}$ is given by

$$
\begin{gathered}
M_{0}=2\left\{(1-\mu r)\left(\frac{R r}{R m}\right)^{2 p}\left[(1-\mu r)+(1+\mu r)\left(\frac{R m}{R s}\right)^{2 p}\right]\right. \\
\left.-(1+\mu r)\left[(1+\mu r)+(1-\mu r)\left(\frac{R m}{R s}\right)^{2 p}\right]\right\} .
\end{gathered}
$$

For an external-rotor coreless zero-cogging Halbach-array motor, the radial flux density at the air gap $B_{r I I I}$ is given by

$$
\begin{aligned}
B_{r I I I}=\frac{4 B r p}{M_{1}(1-p)}(1 & +\mu r) \times\left[1-\left(\frac{R r}{R m}\right)^{p-1}\right] \\
& \times\left[1+\left(\frac{R i}{r}\right)^{2 p}\right]\left(\frac{r}{R r}\right) \cos p \theta
\end{aligned}
$$

where $M_{1}$ is given by

$$
\begin{gathered}
M_{1}=2\left\{(1-\mu r)\left[(1-\mu r)\left(\frac{R r}{R m}\right)^{2 p}+(1+\mu r)\left(\frac{R i}{R m}\right)^{2 p}\right]\right. \\
\left.-(1+\mu r)\left[(1+\mu r)+(1-\mu r)\left(\frac{R i}{R r}\right)^{2 p}\right]\right\}
\end{gathered}
$$

where $p$ is the pole pair number, $\mu_{r}$ is the relative recoil permeability of the magnet, $\theta$ is the relative position of the stator with respect to the rotor, $R r$ is the internal radius of the magnet, $R m$ is the magnet outer radius, $R s$ is the stator outer bore radius, $R i$ is the stator inner bore radius, and $r$ is the mean air-gap radius where the flux density has to be calculated. Hence, the radial flux component of an enclosedrotor configuration can be approximated as the sum of the internal- and external-rotor Halbach configurations.

The radial flux density at the air gap $B_{r \text { enclosed }}$ of an enclosed-rotor coreless zero-cogging Halbach-array motor using discrete magnet segments derived from (15)-(18) is given by

$$
B_{r \text { enclosed }}=h\left(B_{r I}+B_{r I I I}\right)
$$

where $h$ is the Halbach approximation factor newly introduced in order to account for the discretization of magnet segments to form the Halbach array. The analytical modeling of the enclosed-rotor Halbach-array PMBLDC motor is done in MATLAB environment.

\section{Analytical Results And Discussion}

The closed form solution derived in the previous section is used for computing the radial component of the mean air-gap flux density ( $B_{r}$ enclosed) for the enclosed-rotor Halbach-array PMBLDC motor. Fig. 4 gives the variation of the peak airgap flux density at the mean air-gap radius with the pole pair number of the enclosed-rotor Halbach-array PMBLDC motor to be designed. The length of the magnetic flux path in a Halbach magnetized rotor is dependent on the pole pair number, and hence, there exist an optimum number of poles at which the flux density is maximum. The same is not applicable for radial and parallel magnetized machines since, in these cases, the 


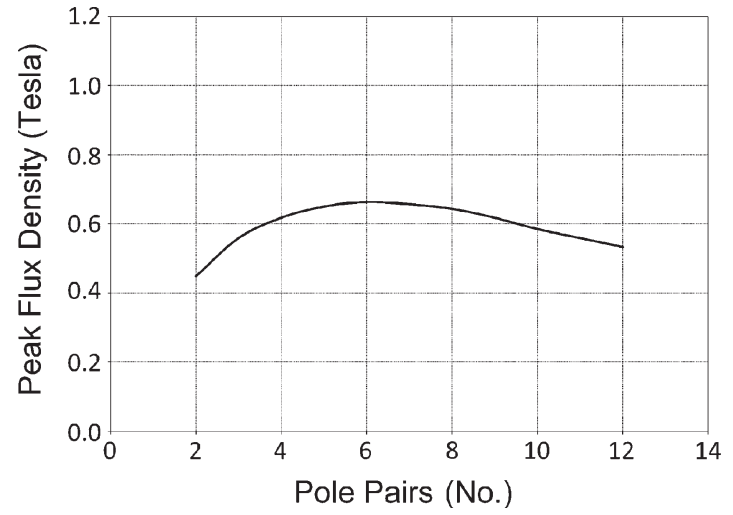

Fig. 4. Variation of peak flux density with change in number of pole pairs.

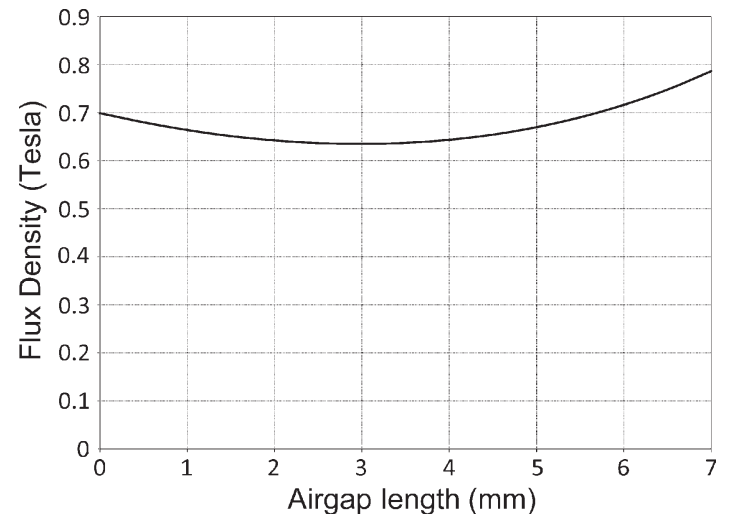

Fig. 5. Variation of air-gap flux density along the length of the air gap.

length of the magnetic flux is constant (equal to the magnetic thickness) [15].

From Fig. 4, it is clear that the peak flux density is obtained at the mean air gap of the machine when the total number of rotor pole pairs is selected as six. Since the motor to be designed is meant for low-speed aerospace applications, optimum performance can be achieved when the total number of rotor poles is selected as high as possible without compromising the flux density of the machine. Hence, the optimum number of the rotor pole pairs for the machine to be designed is selected as eight. Although the increase in the length of the magnet increases the mean air-gap flux density, the space available for accommodating the stator windings gets reduced [18]. Hence, based on the tradeoff between the electrical and the magnetic loading, the optimized values of the length of the magnet and the pole pairs are chosen as $6 \mathrm{~mm}$ and 8 , respectively. Fig. 5 shows the magnetic field variation along the air-gap radius of a Halbach magnetized enclosed-rotor motor configuration where an equal proportion between the main magnet and the flux-focusing magnet is adopted. From this, it is clear that the average value of the peak air-gap flux density along the length of the air gap of the designed motor is $0.68 \mathrm{~T}$ which is very high as compared to that of a conventional Halbacharray slotless machine employing single-rotor configuration. The flux density along the length of the air gap is almost constant because of the presence of PMs on both sides of the air gap which eliminates the possibility of circulating currents in stator conductors, thereby reducing torque ripple. This clearly

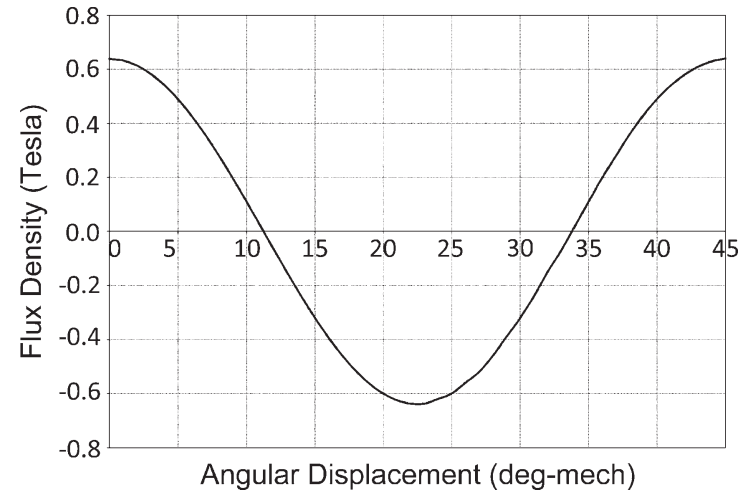

Fig. 6. Variation of mean air-gap flux density under one pole pitch.

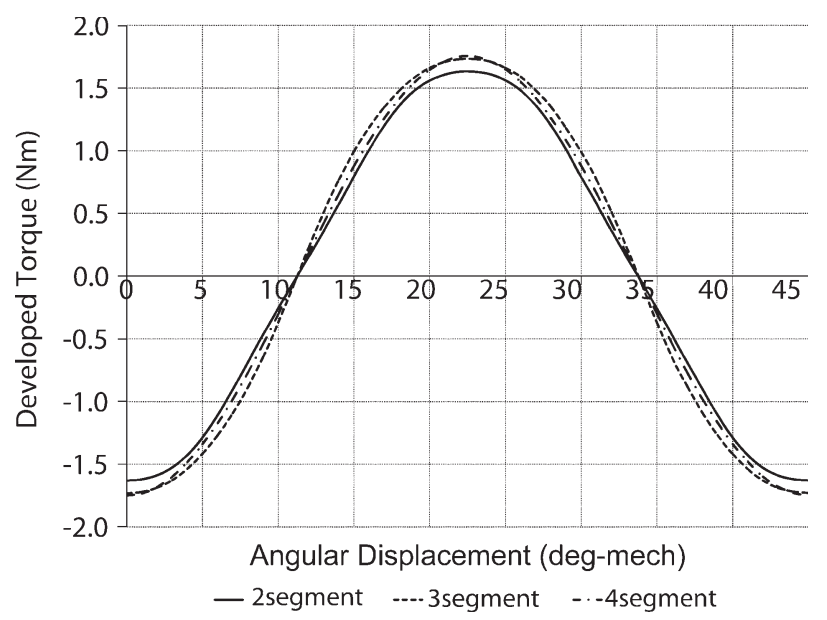

Fig. 7. Developed torque pattern with different numbers of segments per pole of the Halbach array.

is different from a conventional Halbach-array slotless machine where the flux density pattern shows drooping characteristics along the air-gap radius which leads to circulating currents [15]. Fig. 6 shows the mean air-gap flux density variation under one pole pitch of the enclosed-rotor zero-cogging Halbacharray PMBLDC motor which is investigated. Thus, from the analytical modeling of the machine, the length of the magnet and the number of pole pairs of the machine to be designed are obtained as $6 \mathrm{~mm}$ and 8 , respectively.

\section{FE Modeling And Analysis of the Machine}

\section{A. FE Modeling and Analysis}

The basic design parameters obtained from the analytical results of an enclosed-rotor Halbach-array PMBLDC motor such as the length of the magnet and the number of pole pairs are used to model the machine in FE. The optimization of the machine is carried out using a Maxwell FE software package. Two-dimensional FE analysis is carried out as the machine is axisymmetric. Fig. 7 shows the variation of the developed torque pattern when the number of segments per pole of the Halbach array is varied. It is clear that the torque pattern becomes more sinusoidal and approaches ideal Halbach magnetization with the increase in the number of segments which suits well for sine-cosine drives. Since the motor to be designed is a PMBLDC type, a two-segments-per-pole 


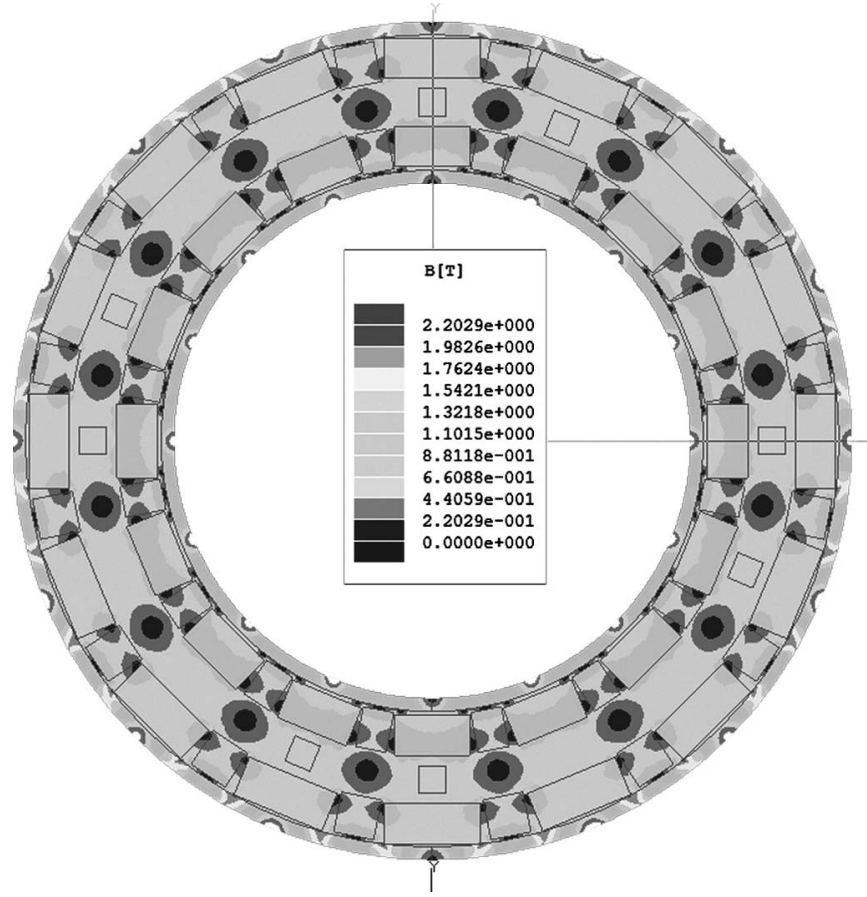

Fig. 8. Flux distribution of the machine.

configuration of the Halbach array is chosen as it produces less torque ripple (less sinusoidal) without much reduction in the torque. Moreover, the fabrication feasibility of the twosegments-per-pole configuration is much superior to that of the other two configurations. Hence, for further analysis and optimization, the number of segments per pole of the Halbach array is selected as two.

From the flux pattern of the two-segments-per-pole Halbacharray enclosed-rotor motor shown in Fig. 8, it is clear that the flux-focusing magnet acts as a path for the flux between adjacent poles and reduces the flux in the back iron. This effect will be clearer with an increased proportion between the fluxfocusing and main magnets.

\section{B. FE Optimization of Enclosed-Rotor Halbach-Array PMBLDC Motor}

The variation of the developed torque pattern with the change in proportion of the flux-focusing magnet and the main magnet is shown in Fig. 9. Here, it is observed that, with the increase in proportion of the flux-focusing magnet to the main magnet, the pattern becomes more sinusoidal with an increased peak torque. The ripple increases (i.e., more sinusoidal) with the increase in proportion of the flux-focusing magnet to the main magnet, which will be more suitable for sine-cosine drives. The variation of peak torque, average torque, and ripple with this change is tabulated in Table I. As per the table, a $20-80$ configuration develops the least torque ripple of $10.79 \%$. However, for the specific spacecraft application of the CMG, a 30-70 configuration of the magnets which provide higher values of peak torque and average torque is chosen without compromising much on the torque ripple.

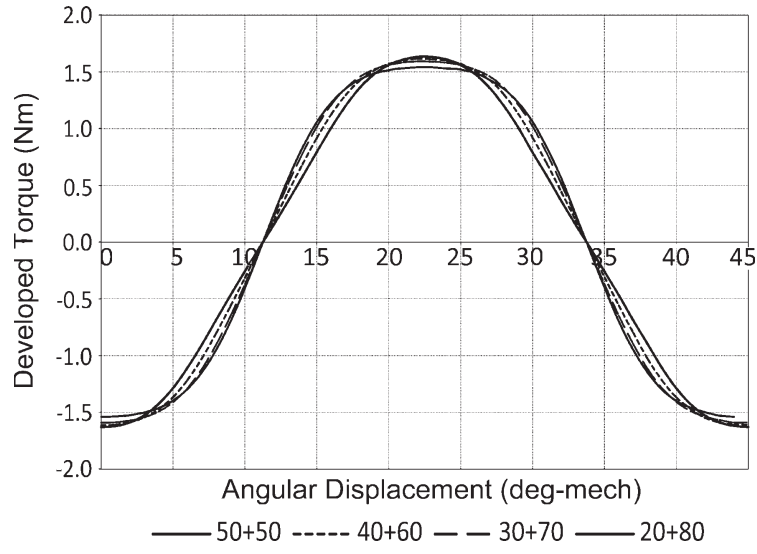

Fig. 9. Developed torque pattern with change in proportion of the fluxfocusing and the main magnet.

TABLE I

Variation of Performance Parameters With the Change in FLUX-FOCUSING MAGNET PROPORTION

\begin{tabular}{ccccc}
\hline \hline $\begin{array}{c}\text { Main } \\
\text { magnet (\%) }\end{array}$ & $\begin{array}{c}\text { Flux focusing } \\
\text { magnet (\%) }\end{array}$ & $\begin{array}{c}\text { Average } \\
\text { Torque } \\
(\mathrm{Nm})\end{array}$ & $\begin{array}{c}\text { Peak } \\
\text { Torque } \\
(\mathrm{Nm})\end{array}$ & $\begin{array}{c}\text { Torque } \\
\text { Ripple (\%) }\end{array}$ \\
\hline 50 & 50 & 1.06 & 1.63 & 22.56 \\
60 & 40 & 1.11 & 1.61 & 16.67 \\
70 & 30 & 1.14 & 1.59 & 12.77 \\
80 & 20 & 1.13 & 1.54 & 10.79 \\
\hline \hline
\end{tabular}

TABLE II

Design Details Developed for the Machine

\begin{tabular}{ll}
\hline \hline Parameter & Value \\
\hline Dimension & $\Phi(123-77) \times 40 \mathrm{~mm}$ \\
Supply Voltage & $28 \mathrm{~V}$ \\
No. of Phases & 3 \\
No. of Poles & 16 \\
No. of Stator coils & 12 \\
Resistance/Phase & $4.5 \Omega$ \\
Air gap thickness & $0.5+0.5 \mathrm{~mm}$ \\
Permanent magnet & $\mathrm{Sm}_{2} \mathrm{CO}_{17}$ \\
No. of magnets & $16+16+32$ \\
Axial Length of magnets & $30 \mathrm{~mm}$ \\
Position sensor & $\mathrm{Hall} \mathrm{element}$ \\
Torque constant & $1.59 \mathrm{Nm} / \mathrm{A}$ \\
Power for 1 Nm at $50 \mathrm{rpm}$ & $8 \mathrm{watts}$ \\
Torque Capability & $6 \mathrm{Nm}$ \\
\hline \hline
\end{tabular}

The design data obtained for the enclosed-rotor Halbacharray PMBLDC motor from analytical and FE analysis are shown in Table II.

Fig. 10 shows the developed torque pattern of the optimized enclosed-rotor Halbach-array PMBLDC motor designed for spacecraft applications. The designed motor is found to deliver $1.59 \mathrm{~N} \cdot \mathrm{m}$ at a 1-A excitation. The developed torque pattern is near trapezoidal because of the increase in proportion of the main magnet to the flux-focusing magnet. 


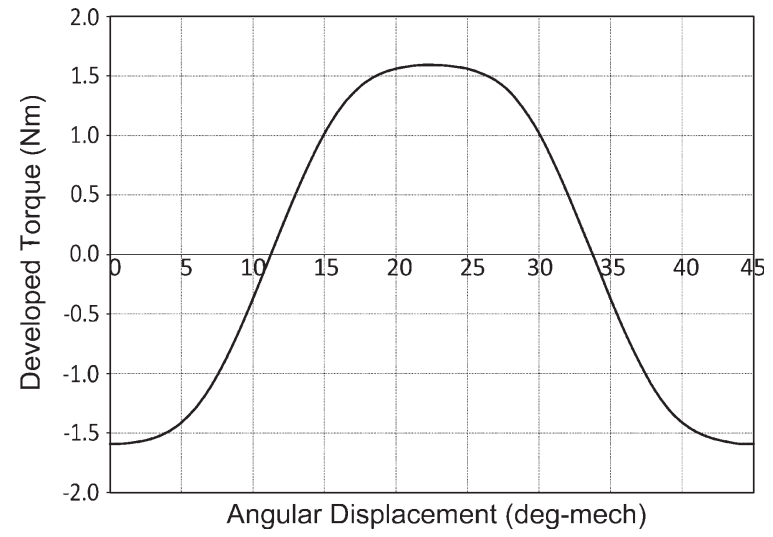

Fig. 10. Developed torque pattern of the optimized enclosed-rotor Halbacharray motor.

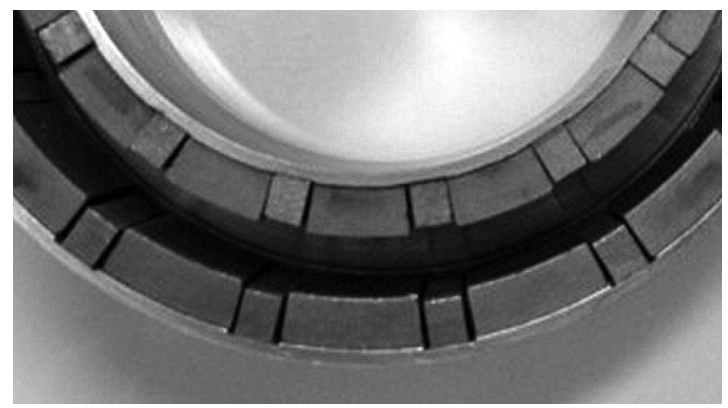

Fig. 11. Enhanced view of the arrangement of Halbach array in the motor.

\section{Vi. Fabrication And Testing of the Machine}

The optimum configuration of the designed enclosed-rotor Halbach-array PMBLDC motor obtained from the analytical and FE results is used for the fabrication of the motor. The motor is fabricated using a wire-cut electrical discharge machine, and the proportion between the flux-focusing magnet and the main magnet is taken as 30-70. Preformed windings are assembled and encapsulated to form the stator assembly. This assembly is then placed in the annular region of the enclosedrotor motor. Although the fabrication of the motor is little difficult and requires processes like wire-cutting technology, the accuracy and other advantages offered by the motor for precise low-speed spacecraft application justify this. The enhanced view showing the arrangement of the Halbach array in the fabricated motor and its final assembled view are shown in Figs. 11 and 12, respectively.

The test rig used for obtaining the static torque characteristics of the fabricated motor is shown in Fig. 13.

The flux density along the air-gap radius of the fabricated machine is nearly constant as obtained from the test results and is plotted in Fig. 14.

The developed torque is measured with the dynamometer test setup. A piezoelectric dynamometer is being used as the torque sensor, and the torque profile is measured by holding the rotor and rotating the stator using the microcontroller-based rotary table. A comparison of the test results of the developed torque pattern of the fabricated motor with FE results for the

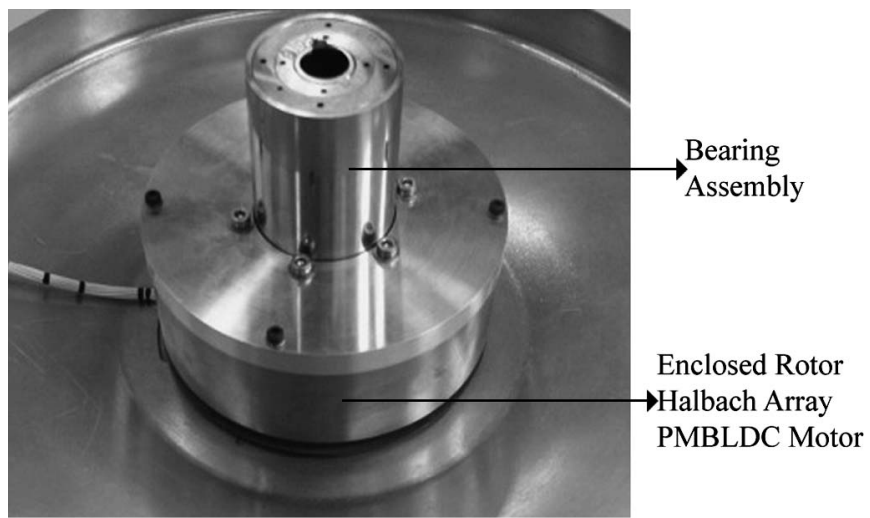

Fig. 12. Assembled view of the fabricated enclosed-rotor Halbach-array PMBLDC motor.

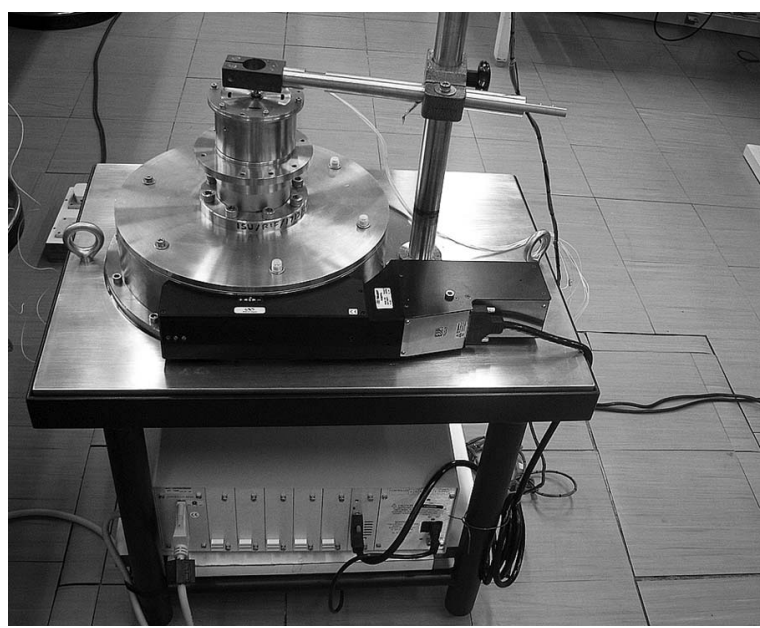

Fig. 13. Experimental test setup of the fabricated motor.

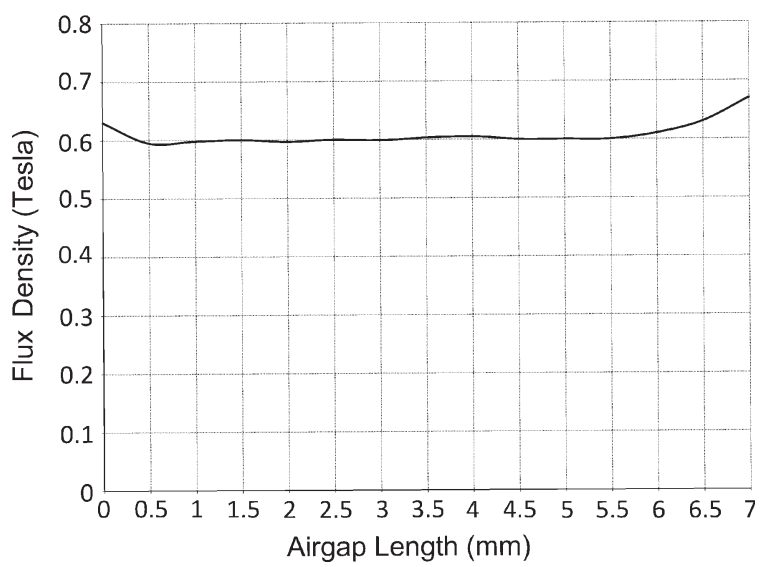

Fig. 14. Variation of air-gap flux density along the length of the air gap (hardware result).

1-A excitation is shown in Fig. 15. The machine is found to develop a peak torque of $1.53 \mathrm{~N} \cdot \mathrm{m}$ at a 1 -A excitation and meet the required design requirements for low-speed spacecraft applications. The hardware test results are found to be in close agreement with the FE results and hence can be used for precise low-speed aerospace applications. 


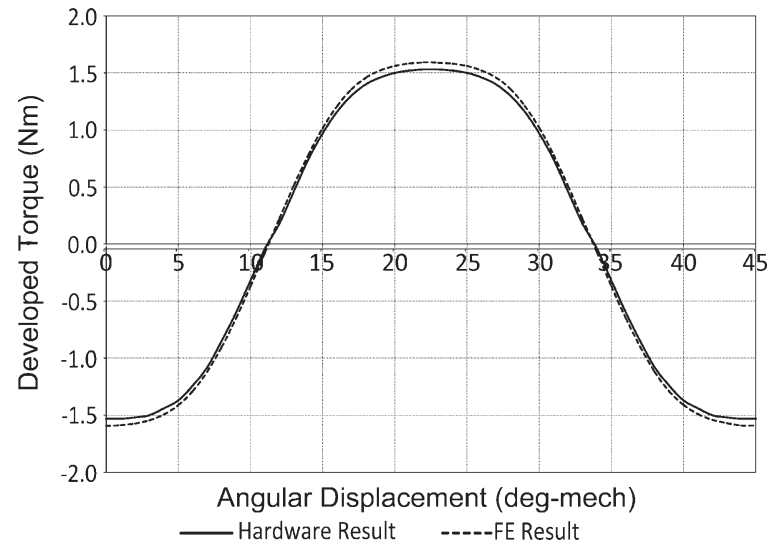

Fig. 15. Comparison of the developed torque pattern obtained from experimental and FE results.

\section{CONCLUSION}

A novel design methodology for an enclosed-rotor zerocogging Halbach-array PMBLDC motor for spacecraft applications is discussed in this paper. The analytical model of the machine has been developed for the initial design and the selection of basic design parameters. The optimization of the machine is carried out in FE. The enclosed-rotor configuration helps in achieving high torque density and uniform flux density along the air gap of the machine, thereby reducing torque ripple. Moreover, the use of the Halbach array helps in achieving a high torque-to-inertia ratio and reduced core losses. The presence of cogging torque and magnetic stiction is also eliminated by employing coreless configuration. The designed machine is fabricated, and the results obtained from analytical and FE methods are validated with experimental results.

\section{ACKNOWLEDGMENT}

The authors would like to thank the ISRO Inertial Systems Unit, Department of Space, Government of India, the Cochin University of Science and Technology, Kerala, India, and the College of Engineering, Trivandrum, Kerala, India, for their help with this project.

\section{REFERENCES}

[1] H. Kurokawa, "A geometric study of single gimbal control moment gyros," Agency Ind. Technol. Sci., Japan, Report of Mechanical Engineering Laboratory, no. 175, p. 108, 1998.

[2] A. Borisavljevic, H. Polinder, and J. A. Ferreira, "On the speed limits of permanent-magnet machines," IEEE Trans. Ind. Electron., vol. 57, no. 1, pp. 220-227, Jan. 2010.

[3] T. Raminosa, C. Gerada, and M. Galea, "Design considerations for a faulttolerant flux-switching permanent-magnet machine," IEEE Trans. Ind. Electron., vol. 58, no. 7, pp. 2818-2825, Jul. 2011.

[4] R. Qu and T. A. Lipo, "Dual-rotor, radial flux, toroidally-wound, permanent magnet machines," in Conf. Rec. IEEE-IAS Annu. Meeting, Pittsburgh, PA, Oct. 2002, vol. 2, pp. 1281-1288.

[5] M. M. El Missiry, "Theory and performance of double-stator hollow rotor motor," in Conf. Rec. IEEE-IAS Annu. Meeting, Atlanta, GA, 1987, vol. 1, pp. 760-767.

[6] A. Toba and T. A. Lipo, "Novel dual-excitation permanent magnet Vernier machine," in Conf. Rec. IEEE-IAS Аnnu. Meeting, Phoenix, AZ, 1999, vol. 4, pp. 2539-2544.

[7] "Selection of electric motors for aerospace applications," NASA Document on Preferred Reliability Practices, pp. 1-6, Practice No. PD-ED1229.
[8] K. W.-H. Tsui, N. C. Cheung, and K. C.-W. Yuen, "Novel modeling and damping technique for hybrid stepper motor," IEEE Trans. Ind. Electron., vol. 56, no. 1, pp. 202-211, Jan. 2009.

[9] R. P. Praveen, M. H. Ravichandran, V. T. S. Achari, V. P. Jagathy Raj, G. Madhu, and G. R. Bindu, "Design and finite element analysis of hybrid stepper motor for spacecraft applications," in Proc. IEEE IEMDC, May 2009, pp. 1051-1057.

[10] R. P. Praveen, M. H. Ravichandran, V. T. S. Achari, V. P. Jagathy Raj, G. Madhu, and G. R. Bindu, "Design and analysis of a hybrid stepper motor for actuating the gimbal of control moment gyroscope," Int. Rev. Elect. Eng. (IREE), vol. 5, pt. A, no. 4, pp. 1488-1495, Aug. 2010.

[11] H. I. Lee and M. D. Noh, "Optimal design of radial-flux toroidally wound brushless dc machines," IEEE Trans. Ind. Electron., vol. 58, no. 2, pp. 444-449, Feb. 2011.

[12] T. Kenjo and S. Nagamori, Permanent Magnet and Brushless dc Motors. Oxford, U.K.: Clarendon, 1985.

[13] T. J. E. Miller, Brushless Permanent Magnet and Reluctance Motor Drives. Oxford, U.K.: Clarendon, 1989.

[14] A. M. El-Refaie, "Fractional-slot concentrated-windings synchronous permanent magnet machines: Opportunities and challenges," IEEE Trans. Ind. Electron., vol. 57, no. 1, pp. 107-121, Jan. 2010.

[15] R. P. Praveen, M. H. Ravichandran, V. T. S. Achari, V. P. Jagathy Raj, G. Madhu, and G. R. Bindu, "Design and analysis of zero cogging brushless dc motor for spacecraft applications," in Proc. IEEE Int. ECTI-CON Conf., May 2010, pp. 254-258.

[16] Z. P. Zia and Z. Q. Zhu, "Analytical magnetic field analysis of Halbach permanent magnet machines," IEEE Trans. Magn., vol. 40, no. 4, pp. 1864-1872, Jun. 2004.

[17] S. M. Jang and S.-S. Jeong, "Comparison of three types of PM brushless machines for an electro-mechanical battery," IEEE Trans. Magn., vol. 36, no. 5, pp. 3540-3543, Sep. 2001.

[18] R. P. Praveen, M. H. Ravichandran, V. T. S. Achari, V. P. Jagathy Raj, G. Madhu, and G. R. Bindu, "Design and analysis of enclosed rotor Halbach array brushless dc motor for spacecraft applications," in Proc. IEEE ICEM, Sep. 2010, pp. 1-6.

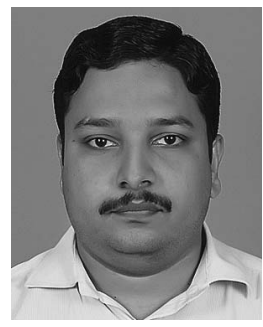

R. P. Praveen received the B.E.degree in electrical and electronics engineering from Manonmaniam Sundaranar University, Tirunelveli, India, in 2004, and the M.Tech. degree in electrical machines from the University of Kerala, Trivandrum, Kerala, India, in 2007.

$\mathrm{He}$ is currently doing his research work at Cochin University of Science and Technology, Cochin, Kerala, India in association with Indian Space Research Organisation Inertial Systems Unit, Trivandrum, India. He is also an Assistant Professor with the Electrical Department of Jyothi Engineering College, University of Calicut, Thrissur, Kerala, India. His research interests include the design, analytical modeling, and optimization of permanent-magnet machines and drives.

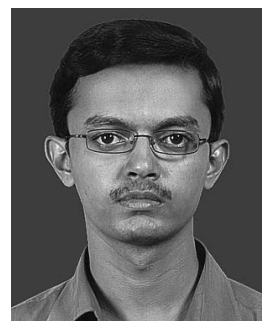

M. H. Ravichandran received the B.E. degree in electrical and electronics engineering from Bharathidasan University, Trichy, India, in 2000, and the M.E. degree in controls and instrumentation engineering from the College of Engineering Guindy, Anna University, Chennai, India, in 2002.

$\mathrm{He}$ is currently with ISRO Inertial Systems Unit, Trivandrum, India, where he has been an Engineer for the last eight years, working on the design, analysis, and development of special electrical machines. His research interests include the design, development, and analytical modeling of special electrical machines like the Permanent-Magnet Brushless dc motors, Switched Reluctance Machines, and hybrid stepper motor. 


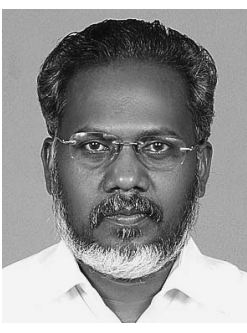

V. T. Sadasivan Achari received the B.Tech. degree in electrical engineering from the University of Kerala, Trivandrum, Kerala, India, in 1982.

He joined Indian Space Research Organisation (ISRO), Trivandrum, India, in 1983 in the Inertial Systems and Instrumentation Division. He has worked extensively in the development of brushless dc motors for inertial actuators like reaction and momentum wheels. His field of interest is in the development of torque motors and design optimization for high torque production.

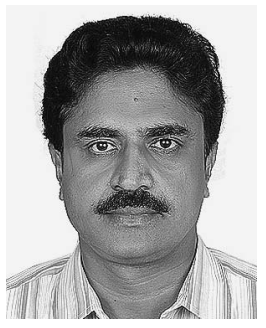

V. P. Jagathy Raj received the B.Tech. degree in electrical and electronics engineering from the University of Kerala, Trivandrum, Kerala, India, the M.Tech. (electronics with communication as specialization) and M.B.A. (systems and operations management) degrees from Cochin University of Science and Technology, Cochin, Kerala, India, and the Ph.D. degree in industrial engineering and management from theh Indian Institute of Technology, Kharagpur, India.

He has more than 20 years of teaching experience in both engineering and management courses both at undergraduate and postgraduate levels. He is currently an Associate Professor with the School of Management Studies, Cochin University of Science and Technology. His research interests include computer simulation and modeling, total quality management, information systems, information communication technology management, reliability, and electrical and electronics engineering.

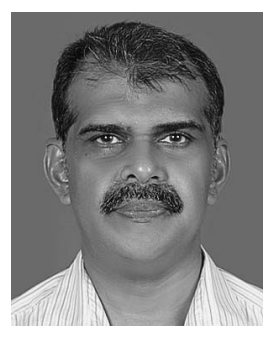

G. Madhu received the B.Tech. degree in engineering from the University of Calicut, Calicut, Kerala, India, in 1984, the M.Tech. degree from the Indian Institute of Technology Madras, Chennai, India, in 1986, and the Ph.D. degree from the Cochin University of Science and Technology, Cochin, India, in 1994.

He has more than 18 years of industrial experience. Since 2004, he has been with the School of Engineering, Cochin University of Science and Technology, as a Professor of Safety Engineering. His research interests include energy management, restoration of environmental quality, and modeling of engineering systems.

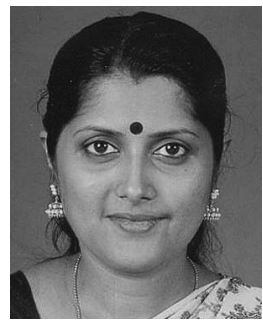

G. R. Bindu was born in Kerala, India, on February 03, 1967. She received the M.Tech. and Ph.D. degrees from the University of Kerala, Trivandrum, Kerala, in 1992 and 2006, respectively.

She was an Engineer with Kerala Kerakarshaka Sahakarna Federation Limited and also a Faculty Member in various engineering colleges in Kerala. She is currently an Associate Professor with the Department of Electrical Engineering, College of Engineering Trivandrum, University of Kerala. Her areas of special interest are electromagnetic field theory, control, and condition monitoring of electric drives. 